\title{
Relationship between nursing workloads and patient safety incidents
}

This article was published in the following Dove Press journal:

Journal of Multidisciplinary Healthcare

25 May 2010

Number of times this article has been viewed

\section{Yuji Nishizaki' \\ Yasuharu Tokuda ${ }^{2}$ \\ Ekiko Sato' \\ Keiko Kato' \\ Akiko Matsumoto' \\ Miwako Takekata' \\ Mineko Terai' \\ Chitose Watanabe ${ }^{3}$ \\ Yang Ya Lim' \\ Sachiko Ohde' \\ Ryoichi Ishikawa'}

'St. Luke's International Hospital, Tokyo, Japan; ${ }^{2}$ Mito Medical Center, University of Tsukuba, Ibaraki, Japan;

${ }^{3}$ Saitama City Hospital, Saitama, Japan

Correspondence:Yuji Nishizaki

St. Luke's International Hospital. 9-I

Akashi-cho, Chuo-ku, Tokyo I04-8560,

Japan

Tel $+8|3354| 5|5|$

Fax +81335440649

Email nishiyu77@gmail.com
Objective: To evaluate the relationship between nursing workloads and patient safety incidents in inpatient wards of a general hospital.

Methods: A retrospective data analysis was conducted involving the internal medicine wards in a teaching hospital in Japan between July 1st and December 31st, 2006. To assess associations between nursing workloads and patient safety incidents, we analyzed the following: the relationships between the level of patients' dependency and the number of incident reports; and the relationships between the presence of accidental falls and the presence of patients transferred from the intensive care unit to the wards.

Results: Fifty-five nurses worked on the wards (105 beds). The total number of incidents was 142 over the 184 days of this study. There was a positive trend between the number of incidents and the total patient dependency score. The presence of accidental falls in the wards was associated with the presence of transfers from the intensive care unit to the wards (odds ratio $3.14,95 \%$ confidence interval: $1.48,6.65)$.

Conclusion: Greater nursing workloads may be related to the higher number of patient safety incidents in inpatient wards of hospitals.

Keywords: risk management, bed control, incident report, patient dependency, nursing care, diagnosis and procedure combination

\section{Introduction}

In order to reduce overall medical costs, an overhaul of the medical fee scheme was conducted by the Health, Labour and Welfare Ministry of Japan. As a result of that overhaul in 2003, they introduced the Diagnosis and Procedure Combination (DPC) payment system into Japanese hospitals. DPC is a fixed payment system per discharge diagnosis and procedure which is used for reducing health care expenditures. DPC is also a system which standardized medical information storage and allowed for the evaluation of quality of medical care. ${ }^{1}$ In hospitals which participated in this new payment system, the hospital stays of patients were forced to be shortened in order for the hospitals to collect payments; therefore, after introducing this new policy, nurses in inpatient wards became busier than before, with increased bed turnovers, including a higher number of transfers of patients from the intensive care units (ICU) to general medical wards and a shortened average length of patient hospital stay. ${ }^{2}$

A work overload situation developed for nurses due to an increasing number of bed turnovers and patient transfers from ICU because of the introduction of DPC. This may 
be considered to be a factor which is associated with patient safety incidents, such as accidental falls of inpatients.

Meurier and colleagues reported that the most common causes of errors were a lack of knowledge or information, work overload, stressful atmosphere and a lack of support from senior staff. Work overload is an important factor to consider for controlling patient safety incidents. ${ }^{3}$

In ICU areas, Stones and colleagues reported that there was a relationship between the working condition of nurses and poor patient outcomes, such as the following: central line associated bloodstream infections; ventilator-associated pneumonia; and, 30-day mortality. ${ }^{4} \mathrm{We}$ must focus on nurses' working conditions and try to control work overload in this new DPC era.

Accidental falls are critical patient safety incidents for inpatients because elderly inpatients are very vulnerable and likely to endure accidental falls. Complications resulting from fall injuries are a leading cause of death in older people. ${ }^{5}$ Rubenstein and colleauges reported that $25 \%$ to $75 \%$ of elderly people who had hip fractures did not recover to their pre-injury functional status; ${ }^{6}$ therefore, we must focus on accidental falls.

Poor working conditions have been associated with burnout of both nurses and physicians. ${ }^{7}$ A stressful atmosphere at work is a major cause of burnout. It was found to be a dangerous factor in depression and in suicides among medical health workers. ${ }^{8}$ We also know shorter sleeping time due to work overload is a cause of patient safety incidents. ${ }^{9}$ We must safeguard nurses' mental health by controlling working hours and conditions.

We must learn from the prior studies mentioned above. We must also create methods of assessment of working conditions for nurses to solve the poor conditions and reduce the number of patient safety incidents, including accidental falls. We know useful indicators for assessment of nursing workload in the ICU area, ${ }^{10}$ but not for the general wards.

This study therefore aimed to evaluate the relationships in this new era of the DPC scheme between the level of patients' dependency and the number of patient safety incidents and between the presence of accidental falls and the presence of patients transferred from the ICU to the wards at a teaching hospital in Japan. The reason why levels of patients' dependency and transfers from ICU were chosen is that the total dependency score of all patients and the workloads related to newly incoming patients with critical illnesses, such as occurs in transfers from an ICU, are likely to predominate over routine nursing tasks in terms of the amount of daily work, among nurses in this new era of the
DPC scheme. In addition to incident reporting, the presence of accidental falls was selected as an indicator of risk management because of its high frequency and its great impact on patients' quality of life and mortality. ${ }^{11,12}$

\section{Methods}

\section{Study setting}

This study was conducted at St. Luke's International Hospital, Tokyo, Japan. This hospital has 520 inpatient beds, an emergency department, and an outpatient walk-in clinic, and it provides primary to tertiary care for about 500,000 people in the Tokyo metropolitan area.

In this hospital, the study was conducted on three internal medicine wards where about 30 patients were admitted constantly each day in each ward. A total of 55 nurses $(21,15$, and 19 for each ward, respectively) worked, based on a two-shift system. The hospital met the distribution criteria for the number of inpatients per nurse (seven patients for one nurse).

\section{Data collection}

\section{Incident reports}

Between July 1st and December 31st, 2006, information on incident reports was collected from the safety management committee of this hospital as a safety measure. The incident reports were required when there were unintended events that could have harmed or did harm a patient. The incidents included the following: procedures; examinations; trouble with intravenous lines and gastric tubes; medication errors; and, accidental falls. Over the same period, daily information was also collected from the safety management committee both on the number of accidental falls, as another safety measure, and on the number of transfers from the ICU to the internal medicine wards as yet another measure of nursing workloads.

\section{Patient dependency score}

Patient dependency scoring information incorporating the degree of nursing care (monitoring and procedures) provided for these patients was collected from daily nursing reports. These scores were recorded daily on electronic medical records by nurses working on the inpatient wards. The scores consisted of 28 items scored from 0 to 1 or from 0 to 2 , as is shown in Table 1. This scoring system is considered a useful objective indicator to assess the workloads of ward nurses in a hospital. ${ }^{13}$

\section{Ethics approval}

We handled delicate observational data, such as clinical incident report data, so ethical approval was necessary. Ethics approval 
Table I The contents of patient dependency scoring system

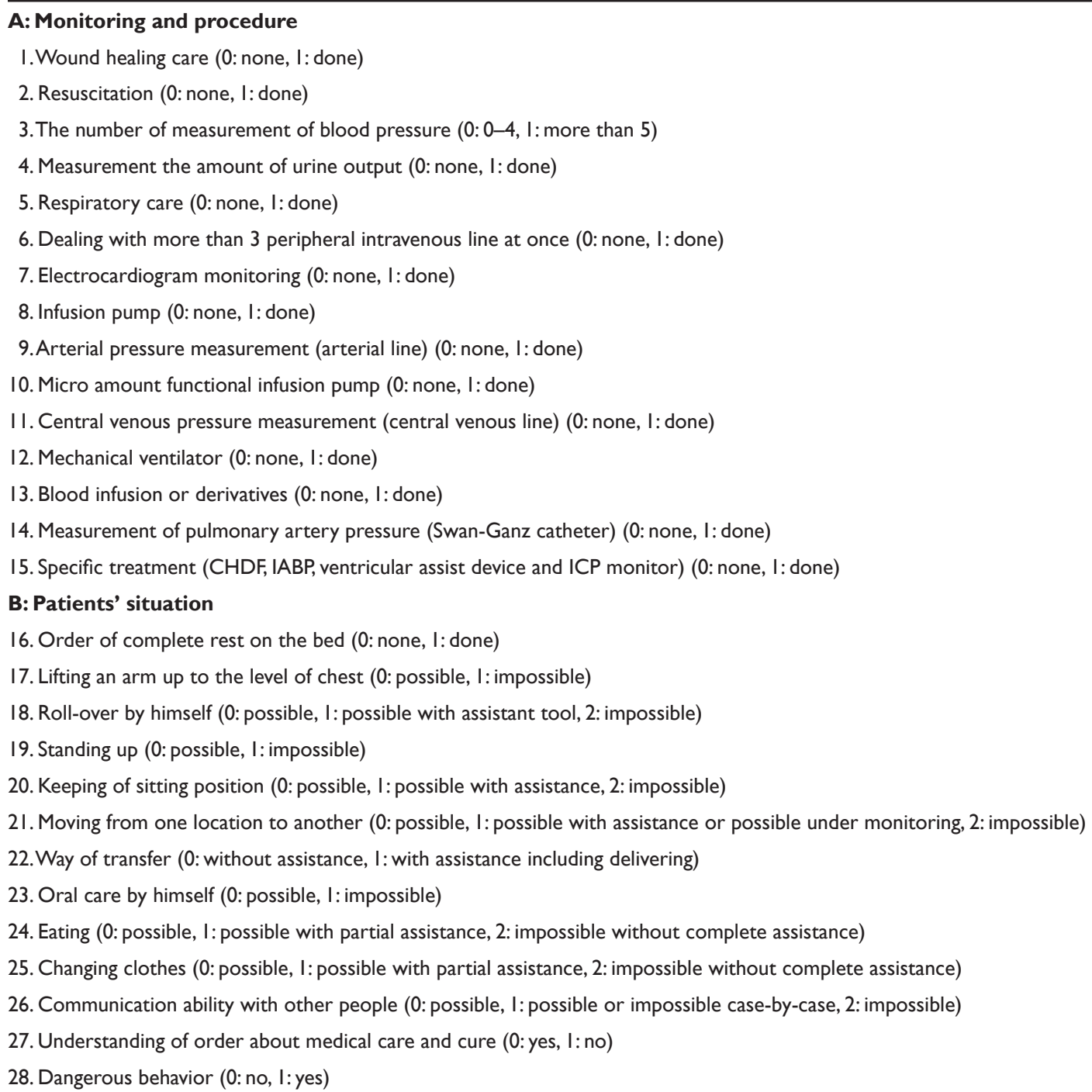

Abbreviations: IABP, Intra-aortic balloon pump; ICP, intracranial pressure monitor; CHDF, continuos hemodiafiltration.

was obtained from the Institutional Review Board of St. Luke's International Hospital (Approval Number: 06-235).

\section{Statistical analysis}

To assess the relationship between the total score of patients' dependency and the number of patient safety incidents, we graphed this data to indicate this relationship clearly.

To assess the relationship between the presence of accidental falls and the presence of patients transferred from the intensive care unit to the wards statistically we firstly described a two-by-two contingency table which consisted of the presence of accidental falls and the presence of patients transferred from the ICU to the wards. We secondly evaluated statistical significance by utilizing chi-square analysis, and then we calculated the odds ratio (OR) of accidental falls by patients transferred from ICU.
All statistical analyses were conducted utilizing SAS Enterprise Guide 4 software (SAS Institute, Cary, NC). Statistical significance was defined as $P<0.05$.

\section{Results}

There was a total of 142 incidents $(57,47$, and 38 for wards $\mathrm{A}, \mathrm{B}$, and $\mathrm{C}$, respectively) on the hospital's internal medicine wards over 184 days. The daily mean numbers of incident reports were $0.31,0.26$, and 0.21 for each ward, respectively. The total patient dependency scores were $54,314,50,404$, and 38,326 for each ward over 184 days, respectively. The daily mean total scores were 295, 274, and 208, respectively. Wards with a higher number of incidents tended to have greater total patient severity scores. Figure 1 shows this trend.

There was a total of 39 accidental falls $(12,18$, and 9 for wards $\mathrm{A}, \mathrm{B}$, and $\mathrm{C}$, respectively) on the hospital's internal 


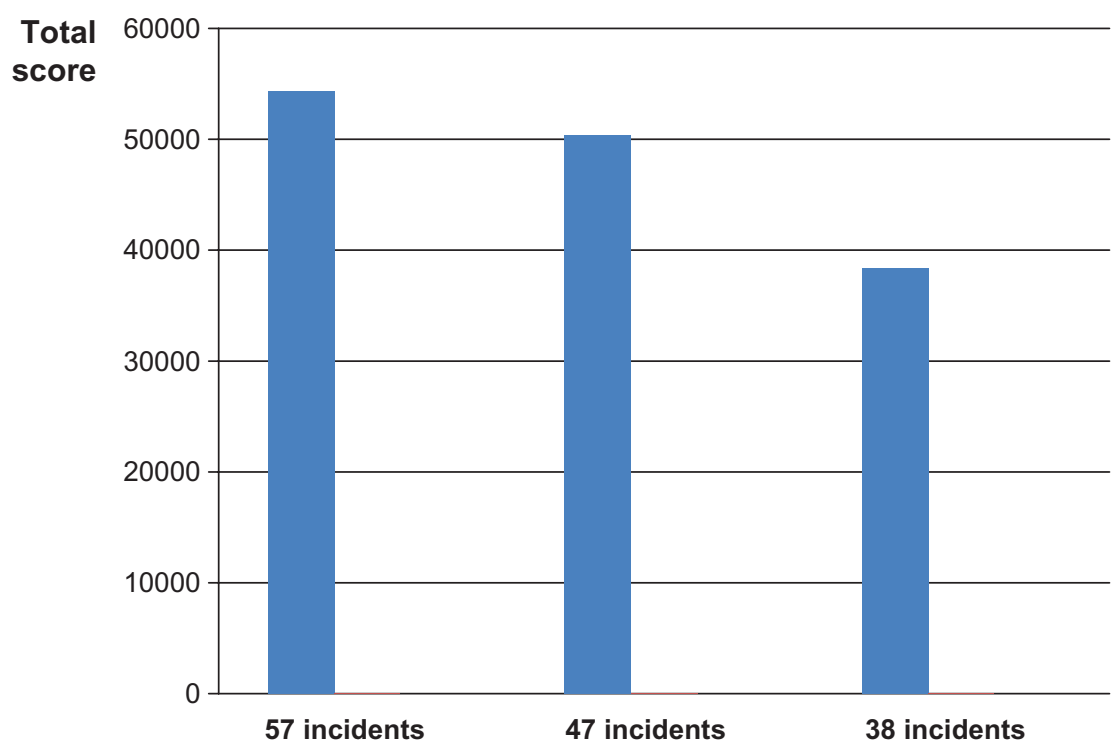

Figure I The association between the number of incidents and total scores of dependency of patients.

medicine wards over 184 days. No more than one accidental fall a day was observed. There was a total of 69 ICU transfers (31, 19, and 19 for wards A, B, and C, respectively) to the hospital's internal medicine wards over 184 days. No more than one ICU transfer a day was observed except for one day which had two ICU transfers. We show basic data of incidents, patients dependency and transfers from ICU in Table 2.

The results of the accidental falls and ICU transfers were as follows: the first category, ICU transfer (+) and accidental fall (+) was 11 days; second category, ICU transfer (+) and accidental fall (-) was 57 days; third category, ICU transfer $(-)$ and accidental fall $(+)$ was 28 days; and, fourth category, ICU transfer (-) and accidental fall (-) was 456 days. We show this two-by-two contingency table data in Table 3 . The results of chi-square analysis utilizing the above mentioned two-by-two contingency table was statistically significant $(P=0.0017)$. The calculation result of the $\mathrm{OR}$ was as follows: OR 3.14, 95\% confidence interval (CI): 1.48, 6.65 .

\section{Discussion}

The results of the present study indicate that a higher patients' dependency score was associated with the occurrence of incidents on our internal medicine wards. Since patient dependency may influence the degree of workload on wards, a bed controller may need to control workloads by limiting transfers from the ICU to wards with a greater dependency score.

The results of the present study also indicate that the presence of transfers from the ICU could be a risk factor for accidental falls. Previous studies focused mainly on patient-related factors as risk factors for accidental falls, but few studies have evaluated the workloads of ward nurses as a possible risk factor. ${ }^{14,15}$ In particular, for acute care hospitals with the DPC scheme, where the number of transfers from the ICU is increasing, this result may be important; moreover, it suggests that a greater number of falls occurs with a higher number of incoming patients.

Table 2 The basic date of incidents, patients dependency and transfers from ICU

\begin{tabular}{lllll}
\hline & Ward A & Ward B & Ward C & Total \\
\hline Total patients dependency score (/I84 days) & $543 \mid 4$ & 50404 & 38326 & 143044 \\
Average patients dependency dairy score (/day) & 295 & 274 & 208 & 777 \\
Total incident number (/I84 days) & 57 & 47 & 38 & 142 \\
Average dairy incident number (/day) & 0.31 & 0.26 & 0.21 & 9 \\
Total accidental fall number (/I84 days) & 12 & 18 & 0.049 \\
Average dairy acidental fall number (/day) & 0.065 & 0.098 & 19 & 39 \\
Total number of transfers from ICU (/I84 days) & 31 & 19 & 0.012 \\
Average dairy number of transfer from ICU (/day) & 0.168 & 0.016 & 69 & 0.20 \\
\hline
\end{tabular}

Abbreviation: ICU, intensive care unit. 
Table 3 Two-by-two contingency table of relationship between ICU transfer and accidental fall

\begin{tabular}{lll}
\hline & Accidental fall $(+)$ & Accidental fall $(-)$ \\
\hline ICU transfer $(+)$ & II (days) & 57 (days) \\
ICU transfer $(-)$ & 28 (days) & 456 (days) \\
\hline
\end{tabular}

Abbreviation: ICU, intensive care unit.

The combined use of the number of transfers and the level of patient dependency may be helpful tools for bed control. Considering these will facilitate decision-making for the allocation of emergency admissions to wards to enable the safe management of patients.

In addition, the preceding study showed a positive correlation between the overwork level and the mental health of medical workers. ${ }^{9}$ Thus, controlling overworking could prevent incidents and could lead to the restoration of ward nurses' mental health; therefore, for both patient safety and nurses' mental health on wards, it is important to appropriately control the workload levels of ward nurses.

The present study had several limitations. Firstly, the ages and job titles of nurses, which may also be influencing the number of incidents and their mental health status were not considered. Secondly, although the number of patients may be a possible risk factor for incidents, the number of patients was not considered; thus, the relationship between the number of patients and incidents was not evaluated. Fourthly, there might have been a selection bias. We conducted our study in only three internal medicine wards. A study involving all wards may be needed to minimize selection bias. Incident reports are self reported, so there might be a discrepancy between the submission rate between wards. Finally, since our study was based on only three wards of a single hospital and had an observational design, the results may not be generalizable. A larger prospective study, as well as a study with an interventional design, will be needed to further validate these results.

Safe patient management is a very important issue for establishing trusting relationships between patients, their families and healthcare providers. This is also related to lower medical costs. ${ }^{16,17}$ Although several theories and methods have been proffered to prevent incidents, ${ }^{18-22}$ some of them are not easily understandable nor applicable. Easily available quantitative indicators, such as the patient severity scores in our study, appear to be useful for managing patient safety by monitoring real-time workloads on hospital wards.

Preventing incidents is also likely to lead to better mental health among nurses working on wards; however, since our conclusion was based on observational data in a single hospital, further study is needed to validate the results. We may need to consider instituting systems solutions for creating a better working environment for nurses. By achieving this, we could reduce the number of patient safety incidents, falls, and nurses' burnout, especially in the era of the DPC and the new medical fee scheme in Japan.

\section{Disclosures}

The authors report no conflicts of interest in this work.

\section{References}

1. Matsuda S. DPC and medical care in the future. What is DPC? Pharmaceuticals Monthly. 2004;46:15-21.

2. The Ministry of Health, Labour and Welfare. Website. 2009. Available from: http://www.mhlw.go.jp/english/index.html. Accessed on February 10, 2010.

3. Meurier CE, Vincent CA, Parmar DG. Learning from errors in nursing practice. JAdv Nurs. 1997;26:111-119.

4. Stone PW, Mooney-Kane C, Larson EL, et al. Nurse working conditions and patient safety outcomes. Med Care. 2007;45:571-578.

5. Sattin RW. Falls among older persons: a public health perspective. Annu Rev Public Health. 1992;13:489-508.

6. Rubenstein LZ, Josephson KR. Falls and their prevention in elderly people: what does the evidence show? Med Clin North Am. 2006;90:807-824.

7. Ruotsalainen J, Serra C, Marine A, Verbeek J. Systematic review of interventions for reducing occupational stress in health care workers. Scand J Work Environ Health. 2008;34(3):169-178.

8. Schernhammer ES, Colditz GA. Suicide rates among physicians: a quantitative and gender assessment (meta-analysis). Am J Psychiatry. 2004;161:2295-2302.

9. Arnedt JT, Owens J, Crouch M, Stahl J, Carskadon MA. Neurobehavioral performance of residents after heavy night call vs. after alcohol ingestion. JAMA. 2005;294:1025-1033.

10. Kiekkas P, Brokalaki H, Manolis E, Samios A, Skartsani C, Baltopoulos G. Patient severity as an indicator of nursing workload in the intensive care unit. Nurs Crit Care. 2007;12:34-41.

11. Center JR, Nguyen TV, Schneider D, Sambrook PN, Eisman JA. Mortality after all major types of osteoporotic fracture in men and women: an observational study. Lancet. 1999;353:878-882.

12. Salkeld G, Cameron ID, Cumming RG, et al. Quality of life related to fear of falling and hip fracture in older women: a time trade off study. BMJ. 2000;320:341-346.

13. Tsutsui T. Structural improvement of medical care by information technology and a degree of nursing care. Japanese Journal of Nursing Administration. 2006;16(9).

14. Harlein J, Dassen T, Halfens RJ, Heinze C. Fall risk factors in older people with dementia or cognitive impairment: a systematic review. J Adv Nurs. 2009;65:922-933.

15. Arfken CL, Lach HW, Birge SJ, Miller JP. The prevalence and correlates of fear of falling in elderly persons living in the community. Am J Public Health. 1994;84:565-570.

16. Bates DW, Leape LL, Cullen DJ, et al. Effect of computerized physician order entry and a team intervention on prevention of serious medication errors. JAMA. 1998;280:1311-1316.

17. Raschke RA, Gollihare B, Wunderlich TA, et al. A computer alert system to prevent injury from adverse drug events: development and evaluation in a community teaching hospital. JAMA. 1998;280: 1317-1320. 
18. Cooper JB, Newbower RS, Long CD, McPeek B. Preventable anesthesia mishaps: a study of human factors. Anesthesiology. 1978;49: 399-406.

19. Cook RI, Woods DD. Operating at the sharp end: the complexity of human error. Bogner MS, editor. Human Error in Medicine. Hillsdale, NJ: Earlbaum Associates; 1994.

20. Reason J. Human Error. Cambridge, MA: Cambridge University Press; 1992.
21. Noman DA. The Psychology of Everyday Things. New York, NY: Basic Books; 1988.

22. Blumenthal D, Scheck AC. Improving Clinical Practice: Total quality management and the physician. San Francisco, CA: Jossey-Bass Publishers; 1995.

\section{Publish your work in this journal}

The Journal of Multidisciplinary Healthcare is an international, peerreviewed open-access journal that aims to represent and publish research in healthcare areas delivered by practitioners of different disciplines. This includes studies and reviews conducted by multidisciplinary teams as well as research which evaluates the results or conduct of such teams or and welcomes submission from practitioners at all levels, from all over the world. The manuscript management system is completely online and includes a very quick and fair peer-review system. Visit http://www.dovepress.com/testimonials.php to read real quotes from published authors.

Submit your manuscript here: http://www.dovepress.com/journal-of-multidisciplinary-healthcare-journal 